\title{
Acetonitrile intoxication impact on humoral and cellular immune responses
}

\begin{abstract}
Experiments on random-bred albino rats showed that acetonitrile chronic intoxication (0.05 LD50 daily for 30 days) equally reduces the immune responses associated with the function of Th1, Th2 and B lymphocytes, decreases the activity of natural killer cells, antibody-dependent cellular cytotoxicity, blood concentrations of immunoregulatory, proinflammatory and anti-inflammatory cytokines (IFN- $\gamma$, IL-2, IL-4, IL-6, IL-10 and IL-13), reduces the acetylcholinesterase activity in T lymphocytes.
\end{abstract}

Keywords: acetonitrile, immunotoxicity, Th1, Th2 lymphocytes, cytokines, T cell acetylcholinesterase
Volume 12 Issue 4 - 2019

\author{
Pavel F Zabrodsky \\ Saratov Medical University REAVIZ, Saratov, Russia
}

Correspondence: Pavel F Zabrodsky, Branch of a private institution of an educational organization Higher education, Saratov Medical University REAVIZ, 4 I 00 I2, Saratov, ul, Upper market, b/n, building 10, Russia, Tel (8452) 74-27-2I, Fax (8452) 26-0I-34,Email saratov@reaviz.ru

Received: June II, 2019 | Published: July 09, 2019

\section{Introduction}

Acetonitrile (AN, ethanenitrile, cyanomethane ethyl nitrile methanecarbonitrile, cyanomethane) is a volatile, colorless, flammable liquid with a smell of ether. MC is widely used in the chemical industry in organic synthesis, the production of aromatic substances, pharmaceutical and perfume preparations, as a selective solvent of hydrocarbons, oils. ${ }^{1-3} \mathrm{AN}$ is one of the most common ligands in coordination chemistry. ${ }^{4}$ High-purity acetonitrile is widely used in high-performance liquid chromatography, gas chromatography, and mass spectrometry, as eluent. ${ }^{5}$ Due to the possible chronic intoxication, $\mathrm{AN}$ in the process of its production and work with it, in case of accidents at chemical plants and contamination of the area can form secondary immunodeficiency states. ${ }^{1,2,6,7}$ At the same time, the study of violations of the parameters of the immune system, in particular, the production of cytokines by lymphocytes and other blood cells, is of both theoretical and practical interest for the prevention and treatment of various infectious complications and diseases arising from AN chronic intoxication. ${ }^{1,2,6,7}$

\section{Aim of the study}

The aim of the study was to evaluate acetonitrile chronic intoxication (0.05 LD50 daily for 30 days) on immune responses, acetylcholinesterase (AChE) activity in $\mathrm{T}$ lymphocytes, and also on blood levels of immunoregulatory, proinflammatory and antiinflammatory cytokine cytokines ( $\gamma$-interferon - IFN- $\gamma$, IL-IL- $\gamma$, IL-1 , IL-4, IL-6 and IL-10 and IL-13).

\section{Materials and methods}

The experiments were performed on random-bred albino rats of both sexes weighing $180-240 \mathrm{~g}$. AN was administered subcutaneously daily for 30 days at a dose of 0.05 LD50 (total dose 1.5 LD50). LD50 of AN for rats after subcutaneous administration was $1750 \pm 95 \mathrm{mg} /$ $\mathrm{kg}$. Immunity system indicators were evaluated by generally accepted methods in experimental Immunotoxicology and immunology $y^{1,2,8}$ after chronic intoxication of AN, 30 days after the first injection of the toxicant. The humoral immune response to T-dependent antigen (red sheep blood cells -RSBC), which characterizes the ability of Th1 cells to participate in the production of IgM by B cells (plasma cells), was determined by the number of antibody-forming cells (AFC) in the spleen 4 days after immunization (peak IgM production) which was administered intraperitoneally at dose of $2 \times 108$ RSBC. Similarly, we evaluated the humoral immune response to a T-independent typhoid $\mathrm{Vi}$-antigen (Vi-Ag), reflecting the function of B cells and the synthesis of IgM by plasma cells (B cells) of the rat spleen. In this case, rats were immunized of Vi-Ag at a dose of $8 \mu \mathrm{g} / \mathrm{kg} .{ }^{1,2,7}$

The function of Th1 lymphocytes also was determined by delayed-type hypersensitivity (DTH) reaction. The DTH was studied in animals by weight gain of the hind paw foot in \%. The resolving dose of RSBC $(5 \times 108)$ was administered under the aponeurosis of foot of the hind paw 4 days after immunization, which was performed intraperitoneally almost simultaneously with the first administered of DChE. The reaction of DTH was evaluated after $24 h^{1,2,7}$

The function of Th2 lymphocytes was investigated by the number of AFC, synthesizing IgG to RSBC, in the spleen after 13 days (peak IgG production $)^{8}$ after immunization $2 \times 108$ RSBC 16 days after the first injection of AN; almost simultaneously with the first administered of AN) by indirect local hemolysis in the gel. ${ }^{1,2,7,8}$ Evaluation of the activity of natural killer cells (NK) and antibody-dependent cellular cytotoxicity (ADCC) was performed by the spectrophotometric method 30 days after the first injection of AN. ${ }^{1,2,7}$ In the control and in the experiments, rats were immunized (108 RSBC) intraperitoneally 15 to 30 minutes after the first administration of AN. AChE activity in T lymphocytes was determined 10, 2030 days after intoxication. The cells were isolated by filtering splenic suspension through Nylon cotton (Nitron). ${ }^{9}$ The tests and estimations were carried out as described previously. ${ }^{9}$ The amount of acetylcholine (in $\mu \mathrm{mol}$ ) hydrolyzed per $1 \mathrm{~min}$ in $1 \mathrm{ml}$ of suspension containing $109 \mathrm{~T}$ lymphocytes was taken for 1 Unit of AChE activity. The concentration of immunoregulatory cytokines IFN- $\gamma$ (\#MBS824935), IL-2 (\#MBS2885949), IL-4 (\#MBS2883072), proinflammatory cytokine IL-6 (\# MBS2885203)) and anti-inflammatory cytokines IL-10 (\#MBS2087187), IL-13 (\#MBS495243) $)^{2,10}$ was examined in rat blood plasma 30days after the first injection of AN using kits (ELISA Kits MyBioSoure) in accordance with the manufacturer's instructions. At the same time, immunization of $2 \times 108 \mathrm{RSBC}$ was performed on day 26 after the first injection of toxicant). Blood for research was taken from the retroorbital venous sinus. The data obtained were processed statistically using the Student's t-test. Differences between the parameters were considered reliable at $p<0.05$. 


\section{Results}

The parameters of T-dependent-AFC to RSBC (IgM), AFC to $\mathrm{RSBC}(\mathrm{IgG})$ after $\mathrm{AN}$ chronic intoxication as well as the T-independent humoral immune response-AFC to $\mathrm{Vi}-\mathrm{Ag}(\operatorname{IgM})$ decreased after 30 days, respectively, in $1.38 ; 1.39$ and 1.42 times $(\mathrm{p}<0.05)$. This suggests that AN chronic intoxication affects T cells and B lymphocytes equally Table 1 . The parameters of cellular immune reactions after exposure to the AN for 30days the activity of NK, ADCC, the reaction of DTH-decreased respectively in 1.40; 1.44 and 1.45 times $(p<0.05)$. The data obtained suggest that humoral and cellular immunity after AN chronic intoxication are affected almost equally. The reduction of Th1 cell function (AFC to RSBC$\mathrm{IgM}$, the DTH reaction) and Th2 lymphocytes (AFC to RSBC-(IgG) occurs equally after AN chronic intoxication. The activity of NK and ADCC to a certain extent depends on the function of T lymphocytes (helpers) of the first type (Th1). The reduction of these parameters, as evidenced by the data Table 2, approximately the same as the Th2 cell-dependent reaction, as well as the humoral immune response, which characterizes the activity of B lymphocytes (AFC to Vi-Ag$\operatorname{IgM})$. There was a decrease equally levels of IFN- $\gamma$, IL-2, IL-4 (immunoregulatory cytokines), IL-6 (proinflammatory cytokine), IL-10 and IL-13 (anti-inflammatory cytokines) in blood after AN chronic intoxication (Table. 2). So, IFN- $\gamma$, IL-2, IL-4, IL-6, IL-10 and IL-13 decreased in $1.34 ; 1.33 ; 1.43 ; 1.51 ; 1.35$ and 1.41 times $(p<0.05)$, respectively. It should be noted that IL- 4 and IL- 6 can also perform anti-inflammatory functions. ${ }^{10}$ After AN chronic intoxication the AChE activity in splenic T lymphocytes in rats 10,20 and 30 days after the first toxicant administration decreased in 1.16 ( $>>0.05) ; 1.38$ and 1.64 times $(\mathrm{p}<0.05)$, respectively (Table 3 ).

Table I The effect of acetonitrile chronic intoxication (total dose- I.5 LD50 30 days) on the parameters of the immune system of white rats $(M \pm m, n=9$ II)

\begin{tabular}{lll}
\hline Parameters & Control & AN \\
\hline AFC to RSBC $(\operatorname{lgM}), 10^{3}$ & $40,5 \pm 4, I$ & $29,4 \pm 2,9 *$ \\
AFC to RSBC $(\operatorname{lgG}), 10^{3}$ & $56,7 \pm 5,5$ & $40,8 \pm 4,3^{*}$ \\
AFC to Vi-Ag $(\operatorname{lgM}), 10^{3}$ & $29,8 \pm 3, I$ & $21,0 \pm 2,3^{*}$ \\
NK activity,\% & $27,9 \pm 2,9$ & $20,0 \pm 2,1 *$ \\
ADCC,\% & $12,8 \pm 1,3$ & $8,9 \pm 1,0^{*}$ \\
DTH reaction,\% & $35,9 \pm 3,7$ & $24,7 \pm 3,0 *$ \\
\hline
\end{tabular}

$*_{-p}<0,05$ as compared to control

Table 2 The effect of acetonitrile chronic intoxication (total dose-I.5 LD50, 30 days) on concentration of cytokines in the rats blood, $\mathrm{pg} / \mathrm{ml}(\mathrm{M} \pm \mathrm{m} ; \mathrm{n}=8-\mathrm{I0})$

\begin{tabular}{lll}
\hline Cytokines & Control & AN \\
\hline IFN- $\gamma$ & $1016 \pm 85$ & $760 \pm 80^{*}$ \\
IL-2 & $1245 \pm 110$ & $933 \pm 94^{*}$ \\
IL-4 & $93 \pm 9$ & $65 \pm 7^{*}$ \\
IFN- $\gamma / I L-4$ & $10,9 \pm I, I$ & $11,7 \pm 1,2$ \\
IL-6 & $127 \pm 13$ & $84 \pm 10^{*}$ \\
IL-I0 & $983 \pm 87$ & $730 \pm 75^{*}$ \\
IL-I3 & $110 \pm 12$ & $78 \pm 8^{*}$ \\
\hline
\end{tabular}

$*_{-p}<0,05$ as compared to control
Table 3 The effect of acetonitrile chronic intoxication on acetylcholinesterase activity in splenic $T$ lymphocytes in rats, $m$ Units/ I09 cells $(M \pm m ; n=9-I I)$

\begin{tabular}{lll}
\hline Duration of intoxication, days & Control & AN \\
\hline 10 & & $55,8 \pm 5,6$ \\
20 & $64,7 \pm 6,5$ & $46,9 \pm 4,7^{*}$ \\
30 & & $39,5 \pm 4,0 * *$ \\
\hline
\end{tabular}

*-p $<0,05$ as compared to control, $* *$ p $<0,05$ compared with the parameter after 10 days

\section{Discussion}

Was established decrease the IFN- $\gamma$ concentration in 1.34times $(\mathrm{p}<0.05)$ and IL-4 concentration-in 1.43 times $(\mathrm{p}<0.05)$ after AN chronic intoxication. The ratio of IFN $\gamma / \mathrm{IL}-4$ in the control was $10.9 \pm 1.1$, and after AN chronic intoxication-11.7 \pm 1.2 . This indicates that the concentrations of IFN- $\gamma$ and IL-4 in the blood are equally reduced under the influence of the $\mathrm{AN}$, therefore the function of Th1 and Th2 lymphocytes is affected equally. ${ }^{2,11}$ The data obtained suggest that the same decrease of Th1 and Th2 lymphocytes activity equally can lead to development, both microbial (the main protective role is played by Th2 lymphocytes and their associated plasma cells, that synthesize immunoglobulins), and viral infection (the main protective role belongs to Th1 lymphocytes along with other T cells, NK and ADCC). ${ }^{2,8,11,12}$ The decrease the IFN- $\gamma$ blood level (immunoregulatory cytokine) is associated with AN damage, mainly Th1-lymphocytes, as well as NK, ADCC, cytotoxic T lymphocytes. ${ }^{13}$ The reduction in blood plasma after $\mathrm{AN}$ chronic intoxication of IL-2 (immunoregulatory cytokine) indicates the suppression of its production by T-cells (including Th0 and Th1 type lymphocytes), a decrease in the proliferation of $\mathrm{T}$ and $\mathrm{B}$ cells, the activity of $\mathrm{NK}$ and ACCD. ${ }^{14}$ The decrease of IL- 6 in the blood (proinflammatory interleukin and in certain cases- the anti-inflammatory cytokine) characterizes the reduction of its synthesis by macrophages, monocytes and lymphoid dendritic cells as a result of their damage of AN and its metabolic products. The decrease the IL-4 concentration in blood (immunoregulatory and, in certain cases, anti-inflammatory cytokine) ${ }^{10}$ is due to AN lesion of Th1 lymphocytes. ${ }^{2,8,10,11}$ The suppression of IL10 synthesis (anti-inflammatory cytokine) under the influence of AN is associated with the defeat of the Th0, Th2 lymphocytes, monocytes, macrophages and $\mathrm{B}$ cells by the toxicant. ${ }^{2,8,11,15}$ The decrease in the blood level of IL-10 to the same extent as IFN- $\gamma$ confirms the established damaging effect of AN on Th1 and Th2 lymphocytes. The reduction of IL-13 (anti-inflammatory cytokine) is due to the AN damage of Th2 lymphocytes, as well as other blood cells. In this case, the modulation of allergic reactions by this cytokine, as well as apoptosis or growth of tumor cells, may be violated. ${ }^{11,16} \mathrm{AN}$ is metabolized to form cyanide (generally about 2-12hours), which is mainly due to its immunotoxic effect due to inhibition of the $\mathrm{a}^{3}$ cytochrome-c-oxidase tissue respiration component in cells of the immune system, as well as more than 40 iron, copper, zinc-containing enzymes. In addition, during the biotransformation of $\mathrm{AN}$, rhodanides, formic acid and ammonia are formed, which, with the exception of rhodanides, have a pronounced immunotoxic effect. ${ }^{1,2,7}$ We have established the anticholinesterase effect of $\mathrm{AN}$, which is associated with decrease of the AChE activity in splenic T lymphocytes after AN chronic intoxication in rats (after 10, 20 and 30 days after the first toxicant administration). The anticholinesterase effect (decrease by AChE activity $\mathrm{T}$ lymphocytes) causes the immunotoxic effect of many toxic chemicals, primarily organophosphorus compounds, ${ }^{2,6,7}$ and to a certain extent acrylonitrile. ${ }^{17}$ 


\section{Conclusion}

a) Acetonitrile chronic intoxication (0.05 LD50 daily for 30 days) equally reduces the activity of Th1 and Th2 lymphocytes, humoral and cellular immune responses.

b) The concentration of immunoregulatory, proinflammatory and anti-inflammatory cytokines (IFN- $\gamma$, IL-2, IL-4, IL-6, IL-10, IL-13) in the blood decreases equally after acetonitrile chronic intoxication.

c) Acetonitrile chronic intoxication reduces the acetylcholinesterase activity in T lymphocytes.

\section{Acknowledgments}

None.

\section{Conflicts of interest}

Authors declare that there are no conflicts of interest.

\section{References}

1. Zabrodskii PF. Immunotropic properties of poisons and drugs. Saratov Saratov State Medical University; 1998. p. 213.

2. Zabrodskii PF, Mandych VG. Immunotoxicology of xenobiotics. Saratov: Military Institute of Biological and Chemical Safety; 2007. p. 420.

3. Patil VS, Nandre KP, Ghosh S, et al. Synthesis and glycosidase inhibitory activity of novel (2-phenyl-4H-benzopyrimedo[2,1-b]-thiazol-4-yliden) acetonitrile derivatives. Bioorganic \& Medicinal Chemistry Letters. 2012:22(23):7011-7014

4. Bocian W, Sitkowski J, Bednarek E, et al. Structure of human insulin monomer in water/acetonitrile solution. Journal of Biomolecular NMR. 2008;40(1):55-64.

5. Ogawa S, Yoshimura E. Comparison of methanol and acetonitrile eluents for the quantitation of chelators specific to soft-metal ions by HPLC Journal of Chromatography B-Analytical Technologies In the Biomedical and Life Sciences. 2012;15(909):34-36.
6. Zabrodskii PF. Influence of xenobiotics on immune homeostasis. In: Kurlyandsky BA, Filov VA, editors. General toxicology. Moscow: Medicine; 2002. p. 352-384.

7. Zabrodskii PF, Kirichuk VF. Changes in nonspecific resistance and humoral and cellular immune reactions after acute acetonitryl poisoning. Bulletin of Experimental Biology and Medicine. 1998;125(5):487-489.

8. Male D, Brostoff J, Roth D, et al. Immunology. 7th edn. Elsevier. 2006. p. 563 .

9. Zabrodskii PF, Germanchuk VG, Kirichuk VF, et al. Anticholinesterase mechanism as a factor of immunotoxicity of various chemical compounds. Bulletin of Experimental Biology and Medicine. 2003;136(2):176-178.

10. Becker KL, Nylén ES, White JC, et al. Clinical review 167: Procalcitonin and the calcitonin gene family of peptides in inflammation, infection, and sepsis: a journey from calcitonin back to its precursors. Journal of Clinical Endocrinology and Metabolism. 2004;89(4):1512-1525.

11. Zabrodskii PF. Immunotoxicology of organ phosphorus compounds. Saratov. 2016. p. 289.

12. Asquith B, Zhang Y, Mosley AJ, et al. In vivo T lymphocyte dynamics in humans and the impact of human T-lymphotropic virus 1 infection. Proceedings of the National Academy of Sciences of the USA. 2007;104(19):8035-8040.

13. Schoenborn JR, Wilson CB. Regulation of interferon-gamma during innate and adaptive immune responses. Advances in Immunology. 2007;96:41101.

14. Nelson BH. Interleukin-2 signaling and the maintenance of self-tolerance. Curr. Dir. Autoimmun. 2002;5:92-112.

15. Said EA, Trautmann L, Dupuy F, et al. Programmed death-1-induced interleukin-10 production by monocytes impairs CD4+ T cell activation during HIV infection. Nat Med. 2010;16(4):452-459.

16. Wynn TA. IL-13 effector functions. Annual Review of Immunology. 2003;21:425-456.

17. Zabrodskii PF, Kirichuk VF, Germanchuk VG, et al. Mechanisms of immunotoxic effects of acrylonitrile. Bulletin of Experimental Biology and Medicine. 2000;129(5):463-465. 